Research Report

\title{
Effect of Different Radiation Times on the Antibacterial Ability of Laser Diodes (650 nm) on Streptococcus mutans
}

\author{
Sri Kunarti ${ }^{1}$, Sukaton ${ }^{1}$, dan Ajeng Hayyuning Citrasari ${ }^{2}$ \\ ${ }^{1}$ Department of Conservative Dentistry, Faculty of Dental \\ Medicine, Airlangga University, Surabaya, Indonesia \\ ${ }^{2}$ Undergraduate Student at Faculty of Dental Medicine, Airlangga \\ University, Surabaya, Indonesia
}

\begin{abstract}
Background: Streptococccus mutans is an acid-producing gram-positive bacterium that colonizes the tooth surface and causes damage to the hard tissue of the tooth. S. mutans is known as the main agent that causes caries. Photodynamic therapy (PDT) consisting of photosensitizers and a light source, such as a laser beam, is considered to have an antibacterial effect on S. mutans. However, the factors that influence the antibacterial effects of the lasers, such as the amount of energy, wavelength, use of photosensitizer, and the duration of radiation still need to be studied. Aim: To determine the effective time(duration) of $650 \mathrm{~nm}$ laser diode radiation as an antibacterial agent against $S$. mutans after 30, 45, 60, and 75 seconds of radiation. Method: 30 samples were divided into 6 groups; (1) S. mutans without methylene blue (MB) and laser, (2) S. mutans with MB, but without a laser, (3) S. mutans with MB and laser for 30 seconds, (4) 45 seconds, (5) 60 seconds, and (6) 75 seconds. After treatment, all samples were cultured and incubated for 48 hours then colony counts were carried out in each group. The results were analyzed using ANOVA and Tukey HSD Test with a $p$ value of $<0.05$. Results: The ANOVA and Tukey HSD test showed a significant difference in each group. Conclusion: $650 \mathrm{~nm}$ laser diode radiation with a duration of 75 seconds is an effective time as an antibacterial against $S$. mutans compared to 30,45 and 60 seconds.
\end{abstract}

Keywords: Streptococcus mutans, methylene blue, laser diode, photodynamic therapy, duration(time).

Correspondence: Sri Kunarti, Department of Conservative Dentistry, Faculty of Dental Medicine, Airlangga University, Surabaya, Indonesia Jl. Mayjend. Prof. Dr. Moestopo no. 47, Surabaya 60132, Indonesia. E-mail: sri-k@fkg.unair.ac.id, +62818340329

\section{INTRODUCTION}

Dental caries is the process of demineralization of enamel and dentine by acids from the metabolism of carbohydrates by cariogenic bacteria residing on dental plaque. ${ }^{1}$ Based on Riset Kesehatan Dasar 2013, the decay, missing, filling-teeth (DMF-T) index illustrates the high rate of caries in Indonesia, which is $4.6 .^{2}$ Untreated caries can allow bacterial activity in it to continue to reach the pulp and can cause irritation resulting in an inflammatory response. ${ }^{3,4}$
In the field of dentistry, maintaining the structure of the tooth's hard tissue is one of the main goals of dental care, especially in conservative dentistry. ${ }^{5}$ Treatment is done by placing a restorative material, such as a filling, on the cavity or missing tooth structure. Before filling the cavity, preparation and disinfection must be carried out to eliminate the carious tissue and bacterial accumulation. ${ }^{6}$

A filling treatment's success is determined in part by the presence or absence of bacteria left on the walls of the 
cavity. The bacteria that remain in the cavity can survive and replicate, causing secondary caries and treatment failure. ${ }^{6}$ Ingredients used such as sodium hypochlorite, chlorhexidine, propolis extract, and treatments such as ozone therapy and laser radiation is considered to have an antimicrobial effect. ${ }^{6}$

Streptococccus mutans is an acidproducing gram-positive bacterium that colonizes the tooth surface and causes damage to the hard tissue of the tooth. $S$. mutans is known as the main agent that causes caries. ${ }^{7} S$. mutans was chosen in this study because it is the dominant bacterium in carious lesions and has been used extensively to evaluate the bactericidal effect on restorative material. ${ }^{8}$

Photodynamic therapy (PDT), which consists of photosensitizers and a light source such as a laser is considered to have an antibacterial effect on $S$. mutans. Laser research in the field of dentistry began in 1960 and still continues to be developed to this day, the diode laser is one that still needs further research. ${ }^{9}$ A diode laser is a semiconductor laser that emits coherent light with a certain wavelength. Among other lasers, diode lasers are the most often used in dentistry. ${ }^{10,11}$

Many studies have tested the antimicrobial effects of lasers on oral bacteria such as Staphylococcus sp., Actinomyces sp., and Streptococcus $s p .^{7}$ Although several studies have proven the antibacterial effect of lasers on $S$. mutans, other factors that can affect the antibacterial effect such as energy intensity, wavelength, the use of photosensitizers, and the duration of radiation are still being studied. ${ }^{12}$ This research was conducted to determine the effective time(duration) of $650 \mathrm{~nm}$ diode laser radiation as an antibacterial agent against $S$. mutans after being given radiation of $30,45,60$ and 75 seconds.

\section{MATERIALS AND METHOD}

Ethical Clearance Certificate: No. 207/HRECC.FODM/VIII/2018. The culture of $S$. mutans was obtained from the $S$. mutans bacterial stock at the Faculty of Dental Medicine Research Center, Airlangga University, Surabaya. Bacterial preparations were incubated in an incubator at $37^{\circ} \mathrm{C}$ and an anaerobic atmosphere for 24 hours. $0.5 \mathrm{ml}$ of the preparation was taken with a micropipette and equated with the McFarland standard of $1.5 \times 108 \mathrm{CFU} / \mathrm{ml}$, then $0.5 \mathrm{ml}$ were each placed into 30 eppendorf tubes.

A total of 30 eppendorf tube samples were grouped into 6 groups, with each group containing 5 tube samples. Group 1 with $S$. mutans was not given Methylene Blue (MB) and no radiation was carried out. Group 2 with $S$. mutans was given MB without radiation. Group 3 with $S$. mutans was given $\mathrm{MB}$ and radiated for 30 seconds. Group 4, group 5 and group 6 was given the same treatment as group 3 but with irradiation times of 45, 60, and 75 seconds respectively.

MB photosensitizer with a concentration of $0.1 \mathrm{mg} / \mathrm{ml}$ was taken as much as $0.5 \mathrm{ml}$ and then transferred to groups $2,3,4,5$, and 6 , then left for preradiation for 1 minute. Radiation was done with Dentolaser FNR diode laser set to $\mathrm{M}=1$ mode or full irradiation mode, and $\mathrm{T}$ (time) according to each group's irradiation time, with an interval of 5 seconds. The laser tip is directed at the mouth of the tube and placed at a distance of $5 \mathrm{~mm}$ against the surface of the media.

$0.1 \mathrm{ml}$ from all samples that have been subjected to treatment are taken and transferred to a TYC agar medium, then incubated at $37^{\circ} \mathrm{C}$ for 48 hours in an anaerobic atmosphere. The number of colonies was counted manually and the results of each group are averaged. 
Data analysis was done using SPSS Statistic Base, normality test was conducted with Kolmogorov-Smirnov, homogeneity test with Levene Test, significance test with ANOVA, and advanced test with Tukey HSD Test, with a $\mathrm{p}$ value of 0.05 .

Table 1. Mean and standard deviations of the $S$. mutans colonies

\begin{tabular}{llll}
\hline Group & N & $\overline{\boldsymbol{x}}(\mathbf{C F U} / \mathrm{ml})$ & SD \\
\hline W/O $\boldsymbol{M B}$ and laser & 5 & 44,4 & 1,14 \\
\hline $\boldsymbol{M B}$ W/O laser & 5 & 38 & 1,58 \\
\hline $\boldsymbol{M B}+\mathbf{3 0}$ seconds & 5 & 25,8 & 0,84 \\
\hline $\boldsymbol{M B}+\mathbf{4 5}$ seconds & 5 & 19,8 & 1,3 \\
\hline $\boldsymbol{M B}+\mathbf{6 0}$ seconds & 5 & 14,6 & 0,55 \\
\hline $\boldsymbol{M B}+\mathbf{7 5}$ seconds & 5 & 9,8 & 0,84 \\
\hline
\end{tabular}

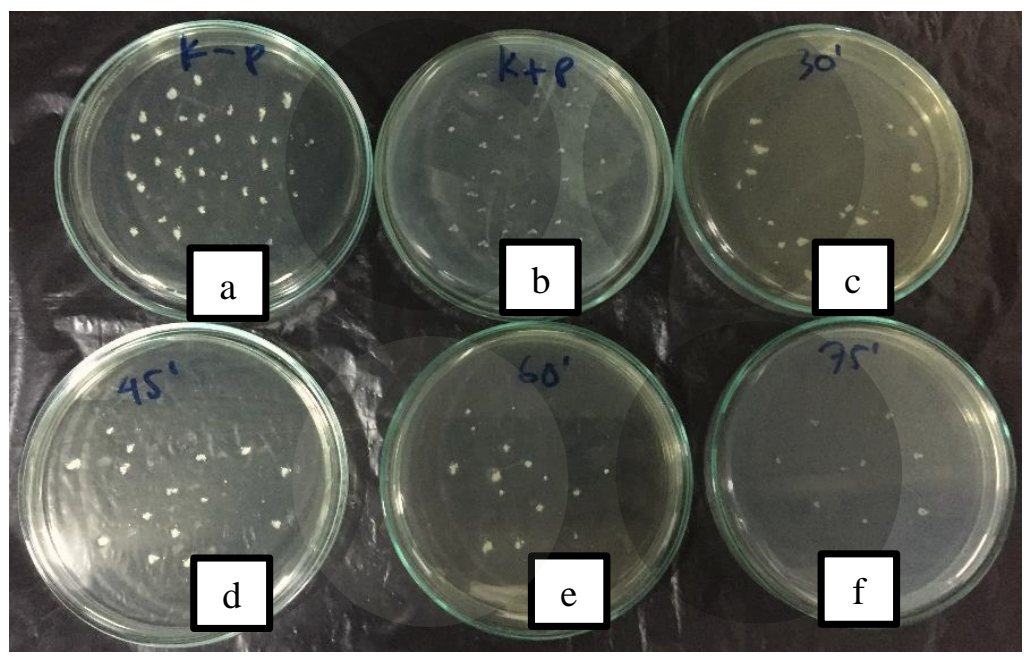

Figure 1. S.mutans bacterial colonies on TYC media. Legend: a. Group 1 (without MB and laser); b. Group 2 (MB without laser); c. Group 3 (MB + 30s); d. Group 4 (MB + 45s); e. Group $5(\mathrm{MB}+60 \mathrm{~s})$; f. Group $6(\mathrm{MB}+75 \mathrm{~s})$.

From the results of data analysis, the Kolmogorov-Smirnov test showed $\mathrm{p}>0.05$ which means normal data distribution. Levene Test test shows p> 0.05 which means homogeneous data variation. ANOVA and Tukey HSD Test showed $p$ value $<0.05$, which means there were significant differences between the number of $S$. mutans colonies in each group (Table 2). 
Table 2. Tukey HSD Test results between groups

\begin{tabular}{ccccccc}
\hline Group & $\mathbf{1}$ & $\mathbf{2}$ & $\mathbf{3}$ & $\mathbf{4}$ & $\mathbf{5}$ & $\mathbf{6}$ \\
\hline $\mathbf{1}$ & - & $.000^{*}$ & $.000^{*}$ & $.000^{*}$ & $.000^{*}$ & $.000^{*}$ \\
\hline $\mathbf{2}$ & - & - & $.000^{*}$ & $.000^{*}$ & $.000^{*}$ & $.000^{*}$ \\
\hline $\mathbf{3}$ & - & - & - & $.000^{*}$ & $.000^{*}$ & $.000^{*}$ \\
\hline $\mathbf{4}$ & - & - & - & - & $.000^{*}$ & $.000^{*}$ \\
\hline $\mathbf{5}$ & - & - & - & - & - & $.000^{*}$ \\
\hline $\mathbf{6}$ & - & - & - & - & - & - \\
\hline Note: $*$ significant difference & & & &
\end{tabular}

\section{DISCUSSION}

In this study photodynamic therapy was carried out using laser diodes as antibacterial agents against $S$. mutans for disinfection of dental cavities. Based on the analysis of the data obtained, there were significant differences in each and every group. This is in accordance with the research of Rikhtegaran et al. who said that photodynamic therapy with MB photosensitizer showed a significant reduction in $S$. mutans. ${ }^{13}$

According to Lozano et al., MB has the maximum ray absorbance rate at a wavelength of $665 \mathrm{~nm} .{ }^{14}$ In the research of Rikhtegaran et al., the use of light with a wavelength of $640 \mathrm{~nm}$ can activate the MB fluid, therefore triggering a photoinactivation process. ${ }^{13}$

MB can interact with bacterial cell walls even without radiation, an oxidation process occurs so that reactive oxygen species (ROS) products are formed which will cause damage to bacterial cell walls. This is evidenced by the difference in group 1 (without $\mathrm{MB}$ and radiation) and group 2 (with MB but without radiation) results, which is significant. ${ }^{15}$

After radiation, a series of photoinactivation processes occurs. The process begins with photosensitization which involves photophysical, photochemical, and photobiological processes. In the photophysical process there is absorption of light by MB and a transition from a low and stable energy state, namely a ground state (S0) becoming an excited single state (S1).
The state of S1 then attempts to return to S0 by passing the triplet state (T1).

Changes in these levels cause chemical reactions to occur, producing singlet oxygen and ROS products that are toxic and can damage target cells. The last process, namely photobiology, is a change that occurs in cells due to the existence of said product, which is the disintegration of the cell wall which will cause lysis of the bacterium. ${ }^{16,17}$

In the T1 phase, there are two processes with different pathways, namely Type I and Type II reactions. In a Type I reaction, electron transfer occurs directly from the photosensitizer under $\mathrm{T} 1$ to the substrate/biomolecule that produces radical products namely superoxide (O2-), hydrogen peroxide $(\mathrm{H} 2 \mathrm{O} 2)$, radial hydroxyl $(\mathrm{OH}-)$, nitric oxide (NO.), and nitrite peroxide (ONOO.). These products will react with S0 to form ROS. In a Type II reaction, energy transfers from the photosensitizer to the receptor, which is oxygen, producing a singlet oxygen (1O2). Oxygen singlets are powerful and dangerous oxidants. ${ }^{18}$

In this study, samples given 30 seconds of radiation already showed some form of antibacterial ability, which was $41.9 \%$, followed by another group given 45 seconds of radiation (55.5\%), 60 seconds $(67.2 \%)$, and the most antibacterial ability obtained was when the samples were given 75 seconds of radiation time (78\%). Gondal \& Amjad said, long exposure times make photons from absorbed lasers increase thus 
making active sites formed on photosensitizers also increase. In the end, the reaction process that occurs, either type I or type II gets longer. Therefore, free radical products, such as ROS and singlet oxygen increases due to the reaction process being longer. ${ }^{19}$

When the samples were given 75 seconds of irradiation time, the antibacterial ability produced was $78 \%$. In order to get maximum antibacterial effect, Xhevdet $e t$ $a l$. said that increasing the exposure time is recommended to get good disinfection results. Non-maximal bacterial elimination may occur at short irradiation times due to the low concentration of ROS formed. ${ }^{20} \mathrm{In}$ addition, this photodynamic therapy can be combined with conventional antibacterial ingredients such as chlorhexidine or sodium hypochloride. ${ }^{21}$

\section{REFERENCES}

1. Al-Mamoori MHK, Ahmed KK, Amer $\mathrm{KH}$, Ramla AA. Effect of $405 \mathrm{~nm}$ Laser Light on the Cariogenic Bacteria Streptococcus mutans. JUBPAS. 2015; 23(4): 1467-73.

2. Department of Health of the Republic of Indonesia. Report on Basic Health Research Results 2013. Jakarta: Balitbangkes; 2013. p.187.

3. Bidar M, Siavash M, Maryam G, Ali T, Farzaneh A, Maryam B. The effect of low level laser therapy on direct pulp capping in dogs. J Lasers Med Sci. 2016; 7(3): 177-83.

4. Goldberg M, Azumi H. The Dental Pulp: Composition, Properties and Functions. JSM Dent. 2017; 5(1): 1079.

5. Qian L, Yanhong M, Junlan W, Xuefang Z, Yanjung Y, Yufeng $M$. Demineralized bone matrix used for direct pulp capping in rats. PLoS ONE. 2017; 12(3): 1-13.

6. Bin-Shuwaish MS. Effects and Effectiveness of Cavity Disinfectants in Operative Dentistry: A Literature Review. J Contemp Dent Pract. 2016;
From this study, it can be said that radiation time is important because the duration of radiation given determines the antibacterial ability produced. The radiation time determines the number of absorbed laser photons so that the ROS and singlet oxygen produced are also quite plentiful to kill $S$. mutans. Even so, excessive exposure time may cause a photothermal effect that can cause damage to surrounding tissues. ${ }^{22,23}$ For this reason, a toxicity test is also needed so that an adequate exposure time can be obtained.

The conclusion of this study is, $650 \mathrm{~nm}$ laser diode radiation with a duration of 75 seconds is an effective time as an antibacterial against $S$. mutans compared to 30,45 , and 60 seconds.

17(10): 867-79.

7. Forssten SD, Marika B, Arthur CO. Streptococcus mutans, Caries, and Simulation Models. Nutrients. 2010; 2 : 290-8.

8. Lee BS, Yueh WL, Jean SC, Tseng TH, Min HC, Chun PL, Wan HL. Bactericidal Effects of Diode Laser on Streptococcus mutans After Irradiation Through Different Thickness of Dentin. Lasers in Surg Med. 2006; 38: 62-9.

9. Komabayashi T, Arata E, Akira A. The Use of Lasers for Direct Pulp Capping. J Oral Sci. 2015; 57(4): 277-86.

10. Pirnat S. Versatility of an $810 \mathrm{~nm}$ Diode Laser in Dentistry: An Overview. J Laser and Health Academy. 2007; 4: 1-9.

11. Derikvand N, Zahra C, Sara G, Nasim C. The Versatility of $980 \mathrm{~nm}$ Diode Laser in Dentistry: A Case Series. J Lasers Med Sci. 2016; 7(3): 205-8.

12. Pereira CA, Anna CBPC, Claudia MC, Juliana CJ, Antonio OCJ. Photodynamic inactivation of Streptococcus mutans and 
Streptococcus sanguinis biofilms in vitro. Lasers Med Sci. 2013; 28: 85964.

13. Rikhtegaran S, Amir AA, Soodabeh K, Elmira J, Leili K, Mahdi R, Tahereh P. Inactivation of Streptococcus mutans Using Photo-activated Disinfection Therapy with Methylene Blue and Indocyanine Green Photosensitizer. J Int Oral Health. 2016; 8(7): 747—52.

14. Lozano PS, Y Gilaberte, MPP Cristobal, LP Artiaga, VL Perez, J Aporta, VP Laguna, IG Luque, MJ Revillo, A Rezusta. In vitro effect photodynamic therapy with differents photosensitizers on cariogenic microorganisms. BMC Microbiol. 2015; $15: 187$.

15. George S, Michael RH, Anil K. Uptake pathways of anionic and cationic photosensitizers into bacteria. Photochem Photobiol Sci. 2009; 8(6): 788-95.

16. Konopka K, Tomasz G. Photodynamic Therapy in Dentistry. J Dent Res. 2007; 86(8): 694-5.

17. Plaetzer K, B Krammer, J Berlanda, F Berr, T Kiesslich. Photophysics and photochemistry of photodynamic therapy: fundamental aspects. Lasers Med Sci. 2009; 24: 259—68.

18. Baltazar LM, Anjana R, Daniel AS, Patricia SC, Adam JF, Joshua DN. Antimicrobial photodynamic therapy: an effective alternative approach to control fungal infections. Front Microbiol. 2015; 6: 3.

19. Gondal MA, \& Amjad K. Rapid disinfection of E-Coliform contaminated water using $\mathrm{WO}_{3}$ semiconductor catalyst by laserinduced photo-catalytic process. J Environ Sci Health A. 2008; 43: 492.

20. Xhevdet A, David S, Igor K, Tomislav J, Miha S, Peter V, Alojz I. The Disinfecting Efficacy of Root Canals with Laser Photodynamic Therapy. J Lasers Med Sci. 2014; 5(1): 24.

21. Mehrvarzfar P, Saghiri MA, Asatourian A, Fakrazad R, Karamifar
K, Eslami G, Dadresanfar B. Additive effect of diode laser on the antibacterial activity of $2.5 \% \mathrm{NaOCl}, 2 \% \mathrm{CHX}$ and MTAD against Enterococcus faecalis contaminating root canals: an in vitro study. J Oral Sci. 2011; 53(3): 35560.

22. Steiner R. Laser tissue-Interaction. Dalam Laser and IPL Technology in Dermatology and Aesthetic Medicine. Editor C Raulin dan S Karsai. Berlin: Springer; 2011. p.23-36.

23. Mortazavi H, Maryam B, Maede M, Niloofar R, Maryam D, Orkideh A, Shalaleh N. Lasers in dentistry: Is it really safe?. Dent Hypotheses. 2016; 7 : $123-7$. 